\title{
Outcomes Associated With Balloon Angioplasty for Recurrent Coarctation in Neonatal Univentricular and Biventricular Norwood-Type Aortic Arch Reconstructions
}

\author{
Wendy Whiteside, ${ }^{1 *}$ MD, Jennifer Hirsch-Romano, ${ }^{2}$ MD, MS, Sunkyung $\mathrm{Yu},{ }^{1} \mathrm{MS}$, \\ Sara K. Pasquali, ${ }^{1} \mathrm{MD}$, MHS, and Aimee Armstrong, ${ }^{1} \mathrm{MD}$
}

\begin{abstract}
Objectives: We evaluated the use of, and outcomes associated with, balloon angioplasty (BA) for recurrent coarctation in single ventricle (SV) and two ventricle (2V) patients following a Norwood-type aortic arch reconstruction (NTAR). Background: Extended patch augmentation of the aorta, a NTAR, is utilized in SV patients undergoing the Norwood procedure (NP) as well as $2 \mathrm{~V}$ patients with a diffusely hypoplastic aorta. While many studies have evaluated recurrent coarctation following the NP, the incidence of recurrent coarctation and outcomes associated with BA in $2 \mathrm{~V}$ patients following NTAR are unclear. Methods: A retrospective review was performed of all neonates who underwent a NTAR at our institution between 2000 and 2010. The incidence of recurrent coarctation requiring intervention and factors associated with successful BA were evaluated. Results: A NTAR was performed in 361 SV patients and 88 2V patients. The incidence of recurrent coarctation requiring intervention was $19.3 \%$ in $2 \mathrm{~V}$ vs. $9.7 \%$ in SV patients $(P=0.01)$ at a median of 0.5 (interquartile range $0.3-1.2$ ) years from initial surgery. BA was successful in $25 \mathrm{SV}$ patients $(81 \%)$ and $102 \mathrm{~V}$ patients $(71 \% ; P=0.70)$. Of the characteristics evaluated, lower initial peak-to-peak gradient $(P=0.02)$, larger balloon size for angioplasty $(P=0.02)$ and larger diameter of the descending aorta $(P=0.01)$ were associated with BA success. Conclusions: Recurrent coarctation following NTAR is more common in $2 \mathrm{~V}$ patients than in SV patients. BA for recurrent coarctation has similar success in both groups and should continue to be utilized in this population. ๑ 2013 Wiley Periodicals, Inc.
\end{abstract}

Key words: recoarctation; coarctation; homograft patch

\section{INTRODUCTION}

Recurrent aortic coarctation is a relatively common complication following the Norwood procedure (NP) as part of the surgical palliation of single ventricle
(SV) anatomy. The incidence of recurrent coarctation following the NP varies widely in the literature, from 2 to $40 \%$ [1-11], and balloon angioplasty (BA) has been shown to be an effective therapy for relief of recurrent
${ }^{1}$ Division of Pediatric Cardiology, Department of Pediatrics, University of Michigan C.S. Mott Children's Hospital, Ann Arbor, Michigan

${ }^{2}$ Section of Pediatric Cardiac Surgery, Department of Cardiac Surgery, University of Michigan, Ann Arbor, Michigan

Conflict of interest: Nothing to report.

*Correspondence to: Wendy Whiteside, MD, University of Michigan Congenital Heart Center, C.S. Mott Children's Hospital, 1540
East Hospital Drive, Ann Arbor, MI 48109.

E-mail: wwhites@med.umich.edu

Received 14 October 2013; Revision accepted 28 November 2013

DOI: $10.1002 / \mathrm{ccd} .25318$

Published online 10 December 2013 in Wiley Online Library (wileyonlinelibrary.com) 
coarctation in this setting with success rates upward of $85 \%$ [3,5,7,11-13]. Few factors have been consistently identified to be associated with an increased risk of recurrent coarctation $[1,9,14,15]$, and there is even more uncertainty as to factors associated with the success or failure of BA in these patients $[11,12]$.

Increased familiarity with the NP in SV patients has allowed translation of a similar technique of aortic reconstruction to the repair of two ventricle (2V) patients with complicated aortic arch anatomy necessitating more extensive aortic arch repair [16,17]. In our center, extended patch augmentation of the aorta in a manner similar to the NP is referred to as a Norwoodtype aortic arch reconstruction (NTAR). The incidence of recurrent coarctation following this type of repair has been reported in only one small series [17] and outcomes of BA in this population have not been previously described. The aim of this study was to evaluate the use, timing, and midterm outcomes associated with BA in $2 \mathrm{~V}$ and SV patients following NTAR and to describe factors associated with BA success.

\section{METHODS}

\section{Study Population}

SV and $2 \mathrm{~V}$ neonates, less than 1 month of age, who underwent a NP or NTAR, respectively, at the University of Michigan Congenital Heart Center between January 2000 and December 2010 were identified using the institutional cardiac surgical database. For this study, a NTAR was defined as extended patch augmentation of the underside of the aorta, extending across the transverse arch, utilizing a median sternotomy and cardiopulmonary bypass. Patients were excluded if they died within 1 month of the initial surgery or had less than 1 month of follow-up available after their initial surgery. Patients who developed significant recurrent coarctation requiring intervention (either catheter based or surgical) were identified by utilizing the Electronic Medical Record Search Engine (EMERSE) system. EMERSE is a web-based tool used to search patient specific information in the University of Michigan Clinical Data Repository, which includes medical documentation from inpatient and outpatient records and allows for automated searches of specific keywords. Using EMERSE, the medical record was searched for the terms "recurrent coarctation," "recoarctation," "aortic arch obstruction," "aortic arch gradient," "residual arch obstruction," and "ascending aortic stenosis." There were no defined parameters to determine the need for intervention and therefore the decision to intervene was at the discretion of the clinical team and made on a case-by-case basis as determined by clinical status, arch gradient, and angio- graphic appearance of the aorta. Patients who had intervention for recurrent coarctation performed at an outside institution were included in determination of recurrent coarctation rate but were excluded from further analysis, as procedural data from the intervention was unavailable.

\section{Data Collection}

Retrospective review of the medical record was performed, and preoperative, operative, and echocardiographic data were collected. Angiographic images for those who underwent cardiac catheterization were reviewed and measurements made using AP and lateral images, as available. For patients with recurrent coarctation, additional data including pre- and postintervention echocardiogram results and procedural characteristics were reviewed. For patients who underwent BA, coarctation index, defined as the ratio of the narrowest arch dimension and the diameter of the aorta at the diaphragm [18], and ratios of the smallest to largest arch dimensions, angioplasty balloon size to the narrowest arch dimension, and angioplasty balloon size to the diameter of the aorta at the diaphragm, were calculated, and location (proximal or distal to the left subclavian artery) and type of coarctation (discrete or long segment) were recorded. Intervention was considered acutely successful if the peak-to-peak aortic arch gradient by catheterization was $\leq 10 \mathrm{~mm} \mathrm{Hg}[5,8]$ in $\mathrm{SV}$ patients and $\leq 15 \mathrm{~mm} \mathrm{Hg}$ in $2 \mathrm{~V}$ patients and was determined retrospectively based upon institutional preferences. Subsequent recoarctation and time to last available follow-up or death were recorded on all patients. The University of Michigan Institutional Review Board approved this protocol with waiver of informed consent.

\section{Statistical Analysis}

Data are presented as frequency with percentage for categorical variables and median with interquartile range (IQR), or mean \pm standard deviation, as appropriate, for continuous variables. Group comparisons between $\mathrm{SV}$ and $2 \mathrm{~V}$ groups were made using chisquare test or Fisher's exact test for categorical variables and Wilcoxon rank-sum test or $t$ test for continuous variables. Similarly, clinical and procedural characteristics were also compared between patients with BA success and those with BA failure to determine potential factors associated with success of BA. Due to small sample size, the SV and $2 \mathrm{~V}$ groups were combined for this comparison. Freedom from recurrent coarctation after initially successful BA was computed using Kaplan-Meier method. All analyses were performed using SAS Version 9.3 (SAS Institute, Cary,

Catheterization and Cardiovascular Interventions DOI 10.1002/ccd Published on behalf of The Society for Cardiovascular Angiography and Interventions (SCAI) 


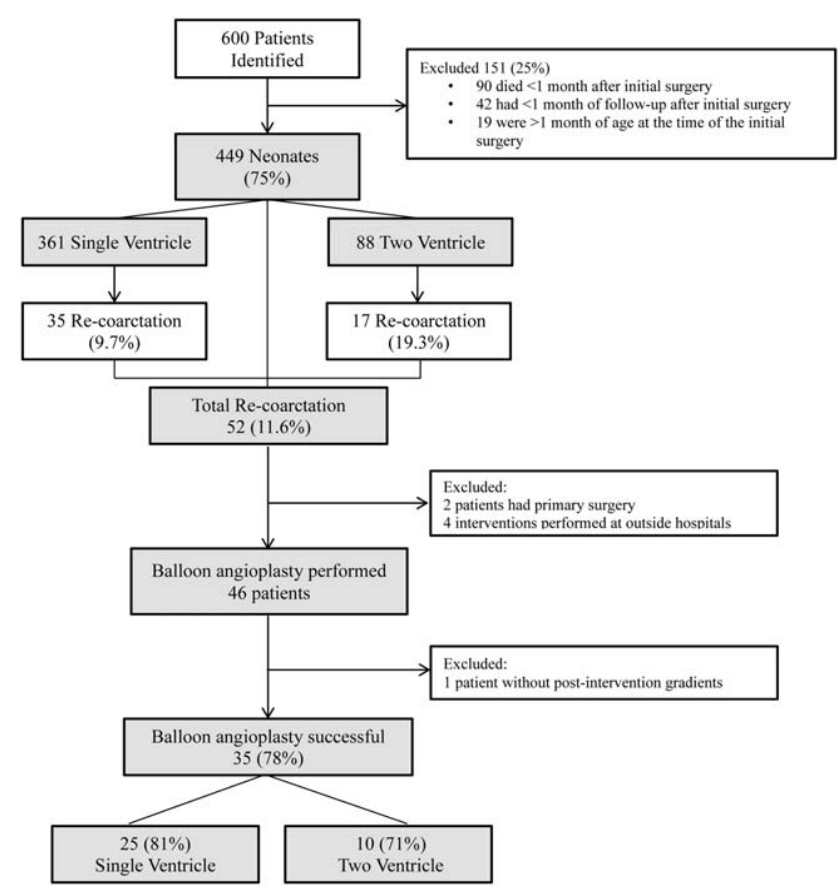

Fig. 1. Flow diagram showing the short-term outcomes of the included study patients.

NC), with statistical significance set at a $P$ value $<0.05$ using a two-sided test.

\section{RESULTS}

\section{Study Population}

A total of 600 patients were identified as having a NTAR during the study period. After applying the exclusion criteria, 449 neonates were included in the final study population. A flow diagram outlining the short-term outcomes of these patients are displayed in Fig. 1. The clinical characteristics of patients who underwent intervention for recurrent coarctation are shown in Table I.

\section{Recurrent Coarctation}

A total of $35 \mathrm{SV}$ patients $(9.7 \%)$ and $172 \mathrm{~V}$ patients $(19.3 \%)$ required intervention for recurrent coarctation $(P=0.01)$. In 46 patients $(88 \%)$ the intervention was a planned procedure with recurrent coarctation suspected by echocardiogram. Preprocedural characteristics of the 46 patients who had BA performed at our center are listed in Table II. SV and 2V groups had similar initial aortic arch gradients as measured by catheterization $(P=0.11)$ but $2 \mathrm{~V}$ patients had a significantly higher peak instantaneous pressure gradients by echocardiogram $(P=0.001)$. All $2 \mathrm{~V}$ patients had normal systemic ventricular function by echocardiogram compared with eight patients $(26 \%)$ in the SV group who had at least moderately depressed systemic ventricular function $(P=0.04)$. While there was

Catheterization and Cardiovascular Interventions DOI 10.1002/ccd.

Published on behalf of The Society for Cardiovascular Angiography and Interventions (SCAI). a trend toward patients with better ventricular function having higher aortic arch gradients, this association was not significant. Likely a reflection of the larger proximal patch created in SV patients to allow for the anastomosis of the two native outflow tracts, SV patients had higher largest aortic arch dimensions $(P=0.01)$.

\section{BA for Recurrent Coarctation}

All but 2 patients underwent BA as the primary intervention for recurrent coarctation at a median of 0.5 years (IQR 0.3-1.2) from their initial surgery. The two patients who had surgery as their primary intervention were SV patients and were repaired surgically because of long segment stenosis in one case and because of a concomitant surgery for another indication in the second case. A retrograde approach for BA through the femoral artery was used in $37(80 \%)$ of patients with an antegrade approach performed in nine SV patients.

Acute success with BA was achieved in $25 \mathrm{SV}$ patients $(81 \%)$ and $102 \mathrm{~V}$ patients $(71 \% ; P=0.70)$. Procedural characteristics of the $\mathrm{SV}$ and $2 \mathrm{~V}$ patients are compared in Table II. Median balloon size chosen was $106 \%$ of the descending aortic diameter at the diaphragm with a significantly higher ratio in SV compared with $2 \mathrm{~V}$ patients (median 109\%, IQR 100-129\% and median $100 \%$, IQR $80-106 \%$, respectively; $P=0.03$ ). Balloon size was 2.2 times the narrowest aortic arch dimension in both groups. There was a reduction in gradient by a median of $83 \%$ (IQR -100 to -64 ) in the SV patients and $74 \%$ (IQR -85 to -55 ) in the $2 \mathrm{~V}$ patients $(P=0.12)$. There were six patients who had procedural complications (13\%); five SV patients $(16 \%)$ and one $2 \mathrm{~V}$ patient $(6.7 \%)$. Complications included transient heart block, bradycardia/hypotension requiring resuscitation, respiratory depression as a result of anesthesia, and death. The one procedural death occurred in a $2 \mathrm{~V}$ patient with preexisting sepsis who was referred for emergent BA. Catheter perforation, pericardial tamponade, and death occurred during the diagnostic portion of the case and BA was not performed. Two patients had small intimal tears noted by postangioplasty angiogram but no patient required intervention or had aneurysm development during the follow-up period. No patient had femoral vessel complications.

\section{Factors Associated With Outcome of BA}

Association of clinical and procedural characteristics with outcome of BA by univariate analysis is shown in Table III. Due to small sample size, the $2 \mathrm{~V}$ and SV groups were combined for this analysis and multivariable analysis was not performed. Among the 45 patients who underwent BA at our 
TABLE I. Patient and Clinical Characteristics of Neonates Who Underwent Any Intervention for Recurrent Coarctation Following NTAR ${ }^{a}$

\begin{tabular}{|c|c|c|c|c|}
\hline \multirow[b]{2}{*}{ Characteristics } & \multirow[b]{2}{*}{ All $(N=52)$} & \multicolumn{2}{|c|}{ Type of anatomy } & \multirow[b]{2}{*}{$P$ value } \\
\hline & & $\mathrm{SV}(N=35)$ & $2 \mathrm{~V}(N=17)$ & \\
\hline Male sex & $28(53.8)$ & $18(51.4)$ & $10(58.8)$ & 0.62 \\
\hline Premature (less than 37 weeks) & $10(19.2)$ & $6(17.1)$ & $4(23.5)$ & 0.71 \\
\hline \multicolumn{5}{|l|}{ Diagnosis for SV patients } \\
\hline HLHS & & $28(80.0)$ & & \\
\hline Other systemic right ventricle & & $4(11.4)$ & & \\
\hline Other systemic left ventricle & & $3(8.6)$ & & \\
\hline \multicolumn{5}{|l|}{ Type of initial shunt in SV patients } \\
\hline Blalock-Taussig shunt & & $23(65.7)$ & & \\
\hline RV-PA shunt & & $11(31.4)$ & & \\
\hline Central & & $1(2.9)$ & & \\
\hline Stage II completed & & $32(91.4)$ & & \\
\hline Fontan completed & & $26(74.3)$ & & \\
\hline \multicolumn{5}{|l|}{ Diagnosis for $2 \mathrm{~V}$ patients } \\
\hline Interrupted aortic arch (IAA) & & & $7(41.2)$ & \\
\hline Coarctation/arch hypoplasia & & & $8(47.1)$ & \\
\hline Other & & & $2(11.8)$ & \\
\hline \multicolumn{5}{|l|}{ Type of $2 \mathrm{~V}$ repair } \\
\hline Arch reconstruction alone & & & $11(64.7)$ & \\
\hline Arch reconstruction and Rastelli & & & $3(17.6)$ & \\
\hline Arch reconstruction and arterial switch operation & & & $3(17.6)$ & \\
\hline Smallest aortic arch dimension (by echo; $N=32 ; \mathrm{mm}$ ) & $2.0(1.7-2.4)$ & $2.0(1.6-2.6)$ & $2.0(2.0-2.0)$ & 0.63 \\
\hline \multicolumn{5}{|l|}{ Surgical factors } \\
\hline Age at (initial) surgical repair (days) & $7(5-9)$ & $6(5-8)$ & $8(6-13)$ & 0.03 \\
\hline Weight at (initial) surgical repair (kg) & $3.1 \pm 0.6$ & $3.1 \pm 0.6$ & $2.9 \pm 0.8$ & 0.36 \\
\hline Cardiopulmonary bypass time (min) & $85(67.5-111.5)$ & $82(67-96)$ & $110(68-165)$ & 0.23 \\
\hline \multicolumn{5}{|l|}{ Follow-up } \\
\hline Deceased & $8(15.4)$ & $6(17.1)$ & $2(11.8)$ & 1.00 \\
\hline
\end{tabular}

Abbreviations: SV, single ventricle; $2 \mathrm{~V}$, two ventricle; HLHS, hypoplastic left heart syndrome; RV-PA, right ventricle to the main pulmonary artery. ${ }^{a}$ Data are presented as $N(\%)$ for categorical variables and median (interquartile range) or mean \pm standard deviation, for continuous variables.

${ }^{\mathrm{b}} P$ value from chi-square test or Fisher's exact test, for categorical variables, and Wilcoxon rank-sum test or $t$ test, for continuous variables, for comparison between $\mathrm{SV}$ and $2 \mathrm{~V}$ patients.

center and had postintervention aortic arch gradients available, male sex, lower initial peak-to-peak gradient measured during catheterization, and larger diameter of the descending aorta at the diaphragm were significantly associated with BA success. While balloon type was not associated with angioplasty success $(89 \%$ used a Tyshak II balloon [NuMED, Hopkinton, NY]), balloon size was associated with success (Table III).

\section{Additional Outcomes}

Over a median follow-up period of 2.3 years (IQR 1.6-5.3) since initial surgery, subsequent recoarctation following an initially successful BA occurred in four SV patients $(11 \%)$. Time to subsequent recoarctation encompassed a wide range from 5.4 months to 9.7 years with all but one case occurring within the first 15 months after initial intervention. Freedom from recurrent coarctation after initially successful BA is shown in Fig. 2. The four patients who had an initially successful BA with subsequent development of recoarctation, had a repeat $\mathrm{BA}$ performed. Of the 10 unsuccessful BA procedures, 2 patients did not undergo repeat intervention, 1 patient underwent repeat BA procedure at 42 days after their initial procedure, and 7 patients proceeded with surgical arch intervention at a median of 6 days (range from 1 day to 50 days) after their initial BA procedure.

\section{DISCUSSION}

This study, evaluating recurrent coarctation in both univentricular and biventricular NTAR, found rates of recurrent coarctation of $19.3 \%$ in the $2 \mathrm{~V}$ population and $9.7 \%$ in the SV population. Despite this difference, however, BA was shown to be equally effective in relief of recurrent coarctation with combined success rates in the SV and $2 \mathrm{~V}$ groups of $78 \%$. In this combined population, lower initial peak-to-peak gradient, larger diameter of the aorta at the diaphragm, and larger angioplasty balloon size were identified as being associated with BA success. 
TABLE II. Preprocedural and Procedural Characteristics of Neonates Who Underwent Balloon Angioplasty as Intervention for Recurrent Coarctation Following NTAR ${ }^{a}$

\begin{tabular}{|c|c|c|c|c|}
\hline \multirow[b]{2}{*}{ Characteristics } & \multirow[b]{2}{*}{ All $(N=46)$} & \multicolumn{2}{|c|}{ Type of ventricle } & \multirow[b]{2}{*}{$P$ value $^{\mathrm{b}}$} \\
\hline & & Single V $(N=31)$ & Two $\mathrm{V}(N=15)$ & \\
\hline Weight at intervention $(N=41 ; \mathrm{kg})$ & $6.4(5.1-9.6)$ & $6.4(4.7-9.6)$ & $6.3(5.4-13.4)$ & 0.65 \\
\hline \multicolumn{5}{|l|}{ Location of coarctation } \\
\hline Proximal & $5(10.9)$ & $3(9.7)$ & $2(13.3)$ & \multirow[t]{2}{*}{0.64} \\
\hline Distal & $40(87.0)$ & $28(90.3)$ & $12(80.0)$ & \\
\hline \multicolumn{5}{|l|}{ Coarctation segment type } \\
\hline Discrete & $40(87.0)$ & $27(87.1)$ & $13(86.7)$ & \multirow[t]{2}{*}{1.00} \\
\hline Long & $5(10.9)$ & $4(12.9)$ & $1(6.7)$ & \\
\hline Preprocedure PIPG by echocardiogram & $40(18-64)$ & $36(21-44)$ & $64(50-75)$ & 0.001 \\
\hline Initial cath peak-to-peak gradient $(\mathrm{mm} \mathrm{Hg})$ & $27(20-40)$ & $26(15-34)$ & $35(25-48)$ & 0.11 \\
\hline Largest balloon size (mm) & $8(7-12)$ & $8(7-12)$ & $8(6-9)$ & 0.10 \\
\hline \multicolumn{5}{|l|}{ Aortic arch dimensions by angiography $(\mathrm{mm})$} \\
\hline Narrowest & $3.7(2.5-5)$ & $3.6(2.7-5.5)$ & $3.9(1.7-4.5)$ & 0.41 \\
\hline Largest & $14(12.5-17.5)$ & $17(13-20)$ & $12(10.8-14)$ & 0.01 \\
\hline Diameter of DAO at diaphragm & $7.8(6.3-10)$ & $7.8(6.7-10)$ & $8(6-10)$ & 0.80 \\
\hline Coarctation index & $0.46(0.38-0.57)$ & $0.49(0.42-0.58)$ & $0.39(0.34-0.44)$ & 0.04 \\
\hline Postprocedure peak-to-peak gradient $(\mathrm{mm} \mathrm{Hg})$ & $5(0-12)$ & $2(0-10)$ & $10.5(5-20)$ & 0.02 \\
\hline
\end{tabular}

Abbreviations: DAO, descending aorta; PIPG, peak instantaneous pressure gradient.

${ }^{\mathrm{a}}$ Data are presented as $N(\%)$ for categorical variables and median (interquartile range) for continuous variables.

${ }^{\mathrm{b}} P$ value from Fisher's exact test for categorical variables and Wilcoxon rank-sum test for continuous variables on comparison between $\mathrm{SV}$ and $2 \mathrm{~V}$ patients.

TABLE III. Association of Clinical and Procedural Characteristics With Outcome of Balloon Angioplasty by Univariate Analysis ${ }^{\mathrm{a}}$

\begin{tabular}{|c|c|c|c|}
\hline \multirow[b]{2}{*}{ Characteristics } & \multicolumn{2}{|c|}{ Success of balloon angioplasty } & \multirow[b]{2}{*}{$P$ value $^{\mathrm{b}}$} \\
\hline & Yes $(N=35)$ & No $(N=10)$ & \\
\hline Male sex & $23(65.7)$ & $1(10.0)$ & 0.003 \\
\hline Age at (initial) surgical repair (days) & $7(5-11)$ & $6.5(5-8)$ & 0.96 \\
\hline Weight at (initial) surgical repair $(\mathrm{kg})$ & $3.2 \pm 0.6$ & $2.8 \pm 0.8$ & 0.14 \\
\hline Cardiopulmonary bypass time (min) & $86(67-112)$ & $80(71-98)$ & 0.59 \\
\hline \multicolumn{4}{|l|}{ Intervention with balloon angioplasty } \\
\hline Age at intervention (years) & $0.5(0.4-1.3)$ & $0.4(0.3-1.1)$ & 0.27 \\
\hline Weight at intervention $(N=41 ; \mathrm{kg})$ & $6.6(5.1-10.9)$ & $5.7(4.6-7.1)$ & 0.51 \\
\hline \multicolumn{4}{|l|}{ Location of coarctation } \\
\hline Proximal & $2(5.7)$ & $3(30.0)$ & 0.06 \\
\hline Distal & $33(94.3)$ & $7(70.0)$ & \\
\hline \multicolumn{4}{|l|}{ Coarctation segment type } \\
\hline Discrete & $32(91.4)$ & $8(80.0)$ & 0.31 \\
\hline Long & $3(8.6)$ & $2(20.0)$ & \\
\hline Initial peak-to-peak gradient $(\mathrm{mm} \mathrm{Hg})$ & $26(15-34)$ & $44(26-60)$ & 0.02 \\
\hline Largest balloon size & $8(7-12)$ & $7(6-8)$ & 0.02 \\
\hline \multicolumn{4}{|l|}{ Aortic arch dimensions (mm) } \\
\hline Narrowest & $3.9(2.7-5.7)$ & $3.0(2.0-3.9)$ & 0.06 \\
\hline Diameter of DAO at diaphragm & $8.5(6.7-10)$ & $6.5(5.0-7.0)$ & 0.01 \\
\hline Coarctation index & $0.46(0.39-0.58)$ & $0.46(0.34-0.54)$ & 0.69 \\
\hline Ratio of balloon size/narrowest aortic diameter & $2.16(1.79-3.03)$ & $2.60(2.05-3.04)$ & 0.34 \\
\hline Ratio of balloon size/DAO diameter & $1.06(0.91-1.20)$ & $1.05(1.00-1.14)$ & 0.60 \\
\hline
\end{tabular}

Abbreviation: DAO, descending aorta.

${ }^{a}$ Data are presented as $N(\%)$ for categorical variables and median (interquartile range) or mean \pm standard deviation, as appropriate, for continuous variables.

${ }^{\mathrm{b}} P$ value from Fisher's exact test for categorical variables and Wilcoxon rank-sum test or $t$ test for continuous variables on comparison between patients with/without success of balloon angioplasty.

The incidence of recurrent coarctation found in our study is comparable to the reported rates of $4-20 \%$ across various types of arch repairs in $2 \mathrm{~V}$ patients Catheterization and Cardiovascular Interventions DOI 10.1002/ccd.

Published on behalf of The Society for Cardiovascular Angiography and Interventions (SCAI).
[17,19-26] and 2-40\% reported from numerous studies in SV patients following the NP [1-6,9-11,27]. Our study is unique, however, in evaluating these groups 


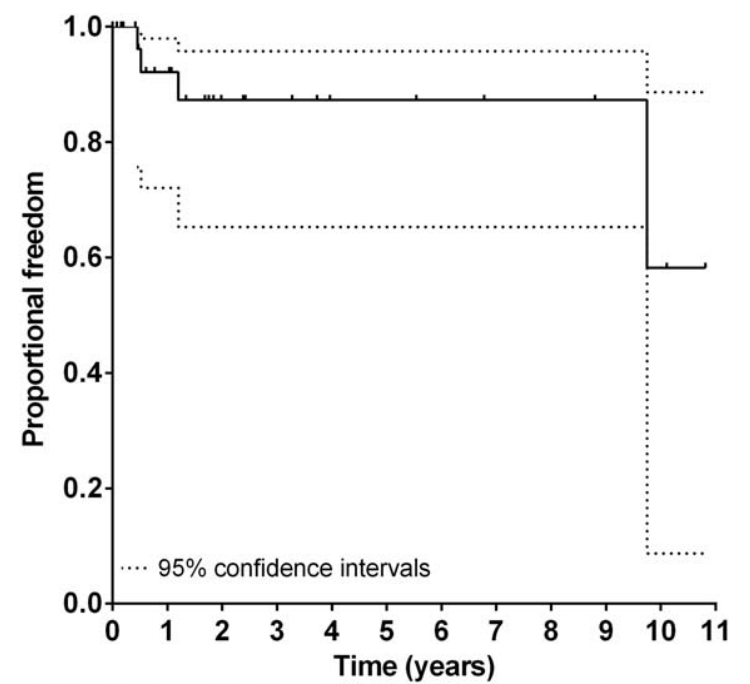

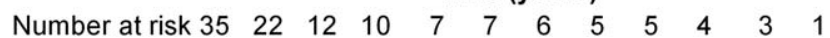

Fig. 2. Kaplan-Meier curve showing freedom from recurrent coarctation after initially successful balloon angioplasty in SV and $2 \mathrm{~V}$ patients combined (with $95 \%$ confidence interval). Freedom from recurrent coarctation was $100 \%$ at 1 month, $96 \%$ at 6 months, $92 \%$ at 1 year, and $87 \%$ at 5 years.

across the same time period using the same group of surgeons and thereby minimizing the effect of variations in surgical technique. While the aortic arch repair may be similar between the $\mathrm{SV}$ and $2 \mathrm{~V}$ groups, differences in intracardiac anatomy remain which may affect flow patterns and aortic growth in ways that cannot be measured by the clinical factors evaluated in this study and which may account for the different recurrent coarctation rates found here between the two groups.

Despite these anatomic differences, BA on a similar type of arch repair was expected to have similar technical success between the SV and $2 \mathrm{~V}$ groups and, in fact, BA is shown in this study to have similarly high success rates in both groups. Variability in the definition of BA success makes it difficult to compare our results directly with prior studies, however our results are comparable to the $74-90 \%$ reported in $2 \mathrm{~V}$ patients following an assortment of traditional aortic arch repairs $[13,28-30]$ and $85-100 \%$ success for SV patients following the NP $[5,7,8,11,12]$. We chose two separate residual pressure gradients to define success in the SV and $2 \mathrm{~V}$ groups as it is our practice to intervene at a lower residual gradient in SV patients who presumably have a limited ability to tolerate residual obstruction.

While success rates of $\mathrm{BA}$ are high, $31 \%$ of the patients who underwent $\mathrm{BA}$ as a primary intervention for recurrent coarctation either had an unsuccessful BA or had subsequent recoarctation requiring an additional intervention. Similar to previous studies, however, our study also has shown that it is difficult to predict which patients may be at higher risk for BA failure. A recent study by Bendaly et al. [11] of 39 patients with recurrent coarctation following the NP found that increased preprocedure gradient and increased ratio of balloon size to size of the descending aorta were associated with BA success. An earlier multicenter study by Soongswang [12] found that earlier time of intervention, increased preprocedure gradient, and increased balloon to coarctation ratio were associated with an increased absolute reduction in peak-to-peak gradient. We found no association with patient age, size, or time from initial surgical procedure with BA success. Increased balloon size, whether this suggests a relatively less severe recoarctation or oversizing of the balloon, is the only factor that seems to be consistent among studies and therefore it remains difficult to guide the choice of intervention and to further prevent development of recurrent coarctation.

\section{Limitations}

Identification of recurrent coarctation was limited to those receiving intervention and therefore patients with unrecognized coarctation or patients who died prior to intervention would be missed. In addition, patients were excluded if they underwent intervention for recurrent coarctation at an outside institution or if they did not have at least 1 month of follow-up available which may have introduced some selection bias in the study population. Finally, due to the small number of angioplasty patients, analysis of factors associated with BA outcomes could only be analyzed with the $2 \mathrm{~V}$ and SV groups combined. While outcomes of BA in the two groups were similar, clinical factors including preoperative and postoperative anatomy were markedly different between groups and may have diluted the results of our risk factor analysis.

\section{Conclusions}

In summary, while the aortic reconstruction of the NP and NTAR are similar, there are differences in the residual intracardiac anatomy and postoperative physiology between these groups which may affect outcomes. Despite these differences, BA is a valuable intervention for relief of recurrent obstruction in both groups with high success rates and few complications. There are no identifiable preprocedural factors and limited intraprocedural factors that predict successful BA but it is still reasonable to attempt BA as first-line intervention in both groups of patients, prior to consideration of surgical repair.

\section{ACKNOWLEDGMENTS}

The authors would like to acknowledge the Michigan Congenital Heart Outcomes Research and Catheterization and Cardiovascular Interventions DOI 10.1002/ccd. Published on behalf of The Society for Cardiovascular Angiography and Interventions (SCAI). 
Discovery (M-CHORD) program for their support of this study, specifically Janet Donohue for assistance with database creation and management. We would also like to acknowledge Dr. David Hanauer for his assistance with the EMERSE tool, provided by the University of Michigan Cancer Center's Biomedical Informatics Core, as well as Ugo Nwokedi and Andrea Yancon for assistance with data collection and entry.

\section{REFERENCES}

1. Ashcraft TM, Jones K, Border WL, et al. Factors affecting longterm risk of aortic arch recoarctation after the Norwood procedure. Ann Thorac Surg 2008;85:1397-1402.

2. Ballweg JA, Dominguez TE, Tabbutt S, et al. Reintervention for arch obstruction after stage 1 reconstruction does not adversely affect survival or outcome at Fontan completion. J Thorac Cardiovasc Surg 2010;140:545-549.

3. Chessa M, Dindar A, Vettukattil JJ, et al. Balloon angioplasty in infants with aortic obstruction after the modified stage I Norwood procedure. Am Heart J 2000;140:227-231.

4. Ishino K, Stümper O, De Giovanni JJV, et al. The modified norwood procedure for hypoplastic left heart syndrome: Early to intermediate results of 120 patients with particular reference to aortic arch repair. J Thorac Cardiovasc Surg 1999;117:920-930.

5. Porras D, Brown DW, Marshall AC, del Nido P, Bacha EA, McElhinney DB. Factors associated with subsequent arch reintervention after initial balloon aortoplasty in patients with Norwood procedure and arch obstruction. J Am Coll Cardiol 2011; 58:868-876.

6. Zellers TM. Balloon angioplasty for recurrent coarctation of the aorta in patients following staged palliation for hypoplastic left heart syndrome. Am J Cardiol 1999;84:231-233.

7. Tworetzky W, McElhinney DB, Burch GH, Teitel DF, Moore P. Balloon arterioplasty of recurrent coarctation after the modified Norwood procedure in infants. Catheter Cardiovasc Interv 2000; 50:54-58.

8. Zeltser I, Menteer J, Gaynor JW, et al. Impact of re-coarctation following the norwood operation on survival in the balloon angioplasty era. J Am Coll Cardiol 2005;45:1844-1848.

9. Lamers LJ, Frommelt PC, Mussatto KA, Jaquiss RDB, Mitchell ME, Tweddell JS. Coarctectomy combined with an interdigitating arch reconstruction results in a lower incidence of recurrent arch obstruction after the Norwood procedure than coarctectomy alone. J Thorac Cardiovasc Surg 2012;143:1098-1102.

10. Hill KD, Rhodes JF, Aiyagari R, et al. Intervention for recoarctation in the single ventricle reconstruction trial: Incidence, risk and outcomes. Circulation 2012;126:A9363.

11. Bendaly EA, Lane KA, Breinholt JP. Balloon angioplasty of recoarctation of the neoaortic arch after the norwood operation: Factors affecting outcome and recurrence. Catheter Cardiovasc Interv 2012;81:97-102.

12. Soongswang J. Outcomes of transcatheter balloon angioplasty of obstruction in the neo-aortic arch after the Norwood operation. Cardiol Young 2001;11:54-61.
13. Yetman AT, Nykanen D, McCrindle BW, et al. Balloon angioplasty of recurrent coarctation: A 12-year review. J Am Coll Cardiol 1997;30:811-816.

14. Bautista-Hernandez V, Marx GR, Gauvreau K, et al. Coarctectomy reduces neoaortic arch obstruction in hypoplastic left heart syndrome. J Thorac Cardiovasc Surg 2007;133:1540-1546.

15. Burkhart HM, Ashburn DA, Konstantinov IE, et al. Interdigitating arch reconstruction eliminates recurrent coarctation after the Norwood procedure. J Thorac Cardiovasc Surg 2005;130:61-65.

16. Tchervenkov CI, Tahta SA, Cecere R, Beland MJ. Single-stage arterial switch with aortic arch enlargement for transposition complexes with aortic arch obstruction. Ann Thorac Surg 1997; 64:1776-8171.

17. Tchervenkov CI, Tahta SA, Jutras L, Beland MJ. Single-stage repair of aortic arch obstruction and associated intracardiac defects with pulmonary homograft patch aortoplasty. J Thorac Cardiovasc Surg 1998;116:897-904.

18. Lemler MS, Zellers TM, Harris KA, Ramaciotti C. Coarctation index: Identification of recurrent coarctation in infants with hypoplastic left heart syndrome after the Norwood procedure. Am J Cardiol 2000;86:697-699.

19. Sandhu SK, Beekman RH, Mosca RS, Bove EL. Single-stage repair of aortic arch obstruction and associated intracardiac defects in the neonate. Am J Cardiol 1995;75:370-373.

20. Kaushal S, Backer CL, Patel JN, et al. Coarctation of the aorta: Midterm outcomes of resection with extended end-to-end anastomosis. Ann Thorac Surg 2009;88:1932-1938.

21. Conte S, Lacour-Gayet F, Serraf A, et al. Surgical management of neonatal coarctation. J Thorac Cardiovasc Surg 1995;109: 663-674; discussion 674-675.

22. Vouhe PR, Trinquet F, Lecompte Y, et al. Aortic coarctation with hypoplastic aortic arch. Results of extended end-to-end aortic arch anastomosis. J Thorac Cardiovasc Surg 1988;96:557-563.

23. Zehr KJ, Marc Gillinov A, Mark Redmond J, et al. Repair of coarctation of the aorta in neonates and infants: A thirty-year experience. Ann Thorac Surg 1995;59:33-41.

24. Messmer BJ, Minale C, Mühler E, Bernuth Gv. Surgical correction of coarctation in early infancy: Does surgical technique influence the result? Ann Thorac Surg 1991;52:594-600.

25. Quaegebeur JM, Jonas RA, Weinberg AD, Blackstone EH, Kirklin JW. Outcomes in seriously ill neonates with coarctation of the aorta. A multiinstitutional study. J Thorac Cardiovasc Surg 1994;108:841-851; discussion 852-854.

26. Knott-Craig CJ, Elkins RC, Ward KE, et al. Neonatal coarctation repair. Influence of technique on late results. Circulation 1993;88:II198-204.

27. Cleuziou J, Kasnar-Samprec J, Hörer J, Eicken A, Lange R, Schreiber C. Recoarctation after the Norwood I procedure for hypoplastic left heart syndrome: incidence, risk factors, and treatment options. Ann Thorac Surg 2013;95:935-940.

28. Hijazi ZM. Balloon angioplasty for recurrent coarctation of aorta. Immediate and long-term results. Circulation 1991;84:1150-1156.

29. Saul JP. Balloon dilation angioplasty of postoperative aortic obstructions. Am J Cardiol 1987;59:943-948.

30. McCrindle BW, Jones TK, Morrow WR, et al. Acute results of balloon angioplasty of native coarctation versus recurrent aortic obstruction are equivalent. J Am Coll Cardiol 1996;28:1810-1817. 